\title{
The Role of Parentese in First Language Acquisition: A Psycholinguistic Study
}

\author{
Titik Sudartinah \\ State University of Yogyakarta
}

\begin{abstract}
This paper discusses one of the major topics in psycholinguistics, language acquisition. It describes how children learn and acquire their first language, as well as the factors affecting the acquisition. Parentese and baby talk, among many other factors, are unique in their nature and characteristics. There are some benefits of using parentese in relation to language leaming: children develop more vocabulary, understand abstract concepts easier, learn grammar naturally, and understand conversation routines.
\end{abstract}

Keywords: first language acquisition, parentese, baby talk

\section{A. Introduction}

Language lies in the central processing system of human beings. It is a very crucial thing they need to survive. Without language, whether spoken or written, a communication might fail. In communication, language is carried out through two basic activities: speaking and listening. In speaking, people put ideas into words and talk about perceptions, feelings, and intentions they want other people to grasp. In listening, they turn words into ideas, try to reconstruct the perceptions, feelings, and intentions to grasp. The process of how people use language is studied under the field of psycholinguisties.

As shown in the name, the term psycholinguistics involves two studies, i.e. psychology and linguistics. Therefore, in it people study how the psychological condition can affect the production and comprehension of a certain language. There are three major topics discussed in psycholinguistics: speech production, speech comprehension, and. language acquisition. The first concems with how 
human can produce speech how to articulate sounds and produce utterances. The second concerns with how human can perceive and comprehend utterances addressed to them, as well as how the language is processed in the brain. The last one concerns with how children acquire and communicate using language.

Each topic in psycholinguistics is interesting to be discussed. However, in this paper, the last topic language acquisition is the one that is being the main discussion. Sometimes, the term acquisition is used only for first language acquisition, while the term learning is preferable than acquisition for second language, i.e. second language leaming. This paper focuses only on how children learn their first language, the nature and characteristics of parentese and baby talk, and the importance of parentese in children's first language acquisition.

\section{B. About First Language Acquisition}

\section{How Children Learn Language}

Most people believe that language is leamed by imitation. Children learn language from their language experiences. They copy and repeat aloud words that they hear. Through imitation, children learn how to pronounce sounds and words and they seem to enjoy imitating the sounds that they hear (Steinberg et al, 2001: 41). However, there is an obvious limitation: imitation can apply only to speech production and not to speech comprehension. Since speech comprehension precedes speech production, imitation cannot be involved in the primary process of language learning, comprehension. Another more obvious limitation is that imitation is not involved in the construction of sentences. Abstract rules cannot be imitated for the simple reason that rules do not exist in the physical world.

Clark and Clark (1977: 296) state that when using a language, children are faced with two general problems. First, they have to figure out how to map their ideas and general knowledge into propositions that they can then express as single words or groups of words. Second, they have to find out how to communicate speech acts and thematic information along with the propositional content of their utterances.

Once children have started to map ideas onto propositions, they can start working out rules for combining words into sentences. They have to focus on the 
structure of the language they are acquiring. At the same time, they have to work on finding out the rules for carrying on conversations. Here, they must focus on the function of language in order to figure out the cooperative principles and all that goes along with it. They have to work at mastering the sound system too. They have to work out which sounds are used in their language and come to recognize them when they are pronounced by others. In short, children acquire their first language first in phonology, then in lexicon and syntactic structure, and later on in semantic meanings.

\section{The Development of Speech Comprehension and Production}

Even long before children have the ability to speak a language, they already have the ability to comprehend utterances addressed to them. Concerning with how they produce speech, there are some stages of language acquisition that young children experience (Steinberg et al, 2001: 6-7):

a. Babbling

Babbling is the period when children start to produce sounds. The sounds are produced in the first few months after birth and include sounds that do and do not occur in the language of the people around them.

b. Holophrastic stage

It is the stage when children start to use one-word utterance. The term holophrastic is composed of holo that indicates whole and phras which indicates phrase or sentence. In this period, children do not only use single words to refer to objects; they also use single words to express complex thoughts which involve those objects. They will use a single word to express the thought for which adults will use a whole sentence. For instance, when a child cries Mommy!, this can have several meanings, such as that he wants his mother to come to him, or that he wants his mother to do something for him. At this stage, children have been shown to understand differences in word order even though they can't produce sentences with different word orders.

c. Telegraphic speech: two- and three-word utterances

Children begin this stage at around 2 years of age. They begin to produce sentences of two words with clear syntactic and semantic relations. As they grow more mature, more complex utterances appear although still many grammatical morphemes are omitted. After this stage, there is an explosion in children's capacity to form sentences and developmental patterns are 
more difficult to describe. The possible purposes of the utterances are indicated, as are some of the semantic relations involved.

\section{Further Development}

Kopp and Krakow (1982) in The Child Development in a Social Context gives a brief description of the stages of children's growth. They state that children at the age of 2 start to play with peers, feel empathy, pride, and embarrassment. They start to enjoy games that entertain them. As for their cognitive development, they can represent ideas with symbols, recall the past, and understand the future. They begin to concentrate doing something they are interested in. They sometimes watch television even though they do not know what actually being shown is. The language, cognitive, and social development change as the age changes.

Further, Kopp and Krakow (1982: 285) state that language is composed of units that are nested into each other and combined in certain ways: The largest of these units, labeled as connected discourse, contains a series of utterances that are related to each other and are produced in a conversation. Conrad in Walton, et al (1972: 274) states that before the age of five children do not use covert speech to memorize, reason, or plan. Instead, they seem to use speech in socially communicative ways to respond impulsively to specific situations, including the naming of objects to other people. It means that children under five do not consider what is meant by words and how to apply them correctly. They enjoy the sounds or the way they can produce the words.

Children everywhere learn to speak at about the same age and make progress at a rate that is roughly much the same. The way children talk would give the hearer a small description about who they are. There are two important terms in children's language development egocentric and sociocentric modes of speech. Egocentrism refers to the children's isolation within themselves they sometimes talk without knowing to whom they speak or whether they are being listened to. The egocentric speech may be expressed through repetition or talking for the sake of talking, monologue or talking to oneself as thinking aloud, and collective or dual monologue.

This is in contrast with socialized speech in which the speaker addresses the listener, considers his point of view, at least to some degrees, and tries to communicate with him. It is only at about the age of seven or eight that true social maturity appears simultaneously with the disappearance of egocentric speech. 


\section{Factors Affecting First Language Acquisition}

Nature and nurture are said to be very important factors in the process of acquiring first language. The concept of nature was proposed by Chomsky in his Universal Grammar, that children all over the world are born with a hard-wired language acquisition device (LAD) in their brains. The $\mathrm{LAD}$ enables human infants to have innate ability for language, without which they would be incapable of learning such complete speech patterns in a natural human environment.

The concept of nurture refers to the way in which children are treated as they are growing, as compared with the characteristics they are born with. In this concept, it is believed that children development is partly because of the treatment from the people surrounding them. The way parents and others treat a child will determine the development level, including the language of the child. First language is picked up at home in the most natural situations. Its learning takes place along with other aspects of biological growth such as walking and governed by the principles of proximity, usefulness, concreteness, particularity, and interest.

Besides nature and nurture, there are some minor factors influencing the success of first language acquisition. They are proposed by Mukalel in $P_{\text {sychology }}$ of Language Learning (2003: 13) as in the following:

a. The physical environment

The materials surrounding a child have a lot to do with what and how he picks up a language. Children get involved in the materials surrounding them much more than adults. Therefore, trees, cats, dogs, etc have a lot to do with the way children learn their first language.

b. The social environment

A child growing up with parents and an orphan one will make a world of difference in language learning. A mother who goes out daily to work and the one who is always by her child will bring different influence toward the child's language learning. The mother, family, and neighborhood are important social elements for the natural language growth of a child.

c. The physical and economic resources

Economic resources influence a child's contact with things and events and possibly limit the range of the child's overall experience. They also determine to a great extent the feasibility of the parents to care for the language development of the child. 


\section{d. Motivation}

There are several internal and external needs which compel children to learn their first language. Among the internal needs are the need for food, warmth, and shelter. There are also emotional needs to fulfill, such as the need for constant love, care, and affection. These needs cannot be met unless the child masters some kind of liaison devices with the world outside. The first language is the most essential of such devices. The need of social interaction requires mastery over a language for interaction with the members of the society. There is the need for self-expression and creative behavior that can be met by language.

Looking closely at all the factors influencing first language acquisition, parentese and baby talk are possible ways to help children acquiring their first language. They both involve the participation of people surrounding a child that make the child exposed to a certain language.

\section{Parentese and Baby Talk}

Of course, when talking to children, adults use different style of language from when they are talking to other adults. Clark and Clark (1977: 322) state that adults talk to young children mainly about 'here and now'. They make running commentaries on what children do or for anticipating their actions. Adults talk about objects that children are interested in. They name, describe the properties, and talk about the relation between objects. There are two terms used to refer to the language used by adults when they are talking to children parentese or motherese and baby talk.

The adults involved in both parentese and baby talk might be the children's parents or others who are in the children's environment. The term parentese refers to the sort of speech that children receive when they are very young (Steinberg etal, 2001: 37). It is often referred to as motherese, caregiver speech, adult-to-child language, and child-directed speech. All of these terms take into consideration the fact that the child receives input from many sources mother, father, siblings, relatives, friends, etc and that such input has special linguistic characteristics. 
On the other hand, the term baby talk which some experts say is the same as parentese is used for referring to a form of parentese that involves the use of vocabulary and syntax that is overly simplified and reduced (Steinberg et al, 2001: 39). Some characteristics of both parentese and baby talk are discussed in the following part.

\section{The Characteristics of Parentese and Baby Talk}

Elliot in her book Child Language (1981: 150) states that the term 'motherese' is the same as 'baby talk' used by Snow and Ferguson in Psychology and Language by Clark and Clark. It displays special modifications of the adult model, particularly at the levels of syntactic, and discourse features.

When adults talk to children, they tend to use simpler language than when they talk to other adults. It is adults who have to adapt themselves to children's language style. The modifications of the language used by adults to children as stated by Elliot (1981: 151) are discussed in the following.

a. Syntactic Features

Concerning with the syntactic features, there are some characteristics that parentese has:

1) Shorter MLU (Mean Length ofUtterance)

MLU (Mean Length of Utterance) is a measure of linguistic productivity in children. It is traditionally calculated by collecting 100 utterances spoken by a child and dividing the number of morphemes by the number of utterances. A higher MLU indicates higher level of language proficiency. The MLU of adult utterances is 7. Therefore, when talking to children, adults' utterances have fewer MLU.

2) Fewer Verb Forms and Modifiers

Adults also minimized using verb forms and modifiers when talking to young children. In English, the present verb form is more preferable than the past one.

3) Fewer Subordinate Clauses per Utterance .

Adults use simpler utterances when talking to children. They usually use only one clause in each utterance and avoid using complex utterances to children. 
4) More Verbless Sentences.

A verbless sentence is a sentence that is grammatically incorrect, since it has no predicate (no verb). However, it can be analyzed as consisting of grammatical units functioning as subject, object etc. Some examples of verbless sentences are questions, commands, and elliptical responses.

5) More Content Words, Fewer Function Words

Content words or open class words are easier to be understood by children since they have clear referents. Words that are considered as content words are nouns, adjectives, verbs, numerals, and interjections.

b. Discourse Features

The discourse features found in the utterances of adults to children are:

1) More Interrogatives and Imperatives

Interrogative and imperative are used more often than other kinds of sentence when adults talk to children. The reason is very obvious: the interrogative is used for encouraging children to give response and the imperative is used for giving commands or request. Therefore, utterances such as Do you want some cookies? or Come here. Mommy have something for you. are common for children.

2) More Fluent and Intelligible Speech

Adults' speech to children are usually fluent and intelligible. Fluent means speaking in a smooth and easily way. Being intelligible means using the simplest language, which is usually indicated by the use of simple words and simple sentence structure. As stated by Clark and Clark (1977: 326), an adult's utterance to other adults usually consist of more than 10 words. Thus, when talking to children, adults use less than 10 words in an utterance.

3) More Repetitions

Using many repetitions is one of the characteristics of adults' utterance to children. By using more repetitions, children will get the meaning of the utterance easier. The repetition might be done completely or partially. Complete repetition refers to the repetition of the whole 
utterance, such as in Mommy is coming! Mommy is coming! When the repetition is done partially, only parts of the utterance that are repeated, such as in Mommy ... Mommy is coming!

Besides Elliot, Clark and Clark also state some characteristics of adults' utterances to children. They are:

a. Almost $100 \%$ of the utterances addressed to children aged two are followed by a pause. The number is decreasing along with the increase of the age of the children.

b. Once children begin to see one and two-word utterances, adults begin to provide both implicit and explicit information about conversational turns. For example, they may provide model dialogues in which the same speaker asks a question and then supplies an answer to it.

c. Adults seldom correct what children have to say. When they do it, they only seem to do it to make sure that the child's contribution is true. The correction is made explicitly or implicitly.

d. Adults use very short sentences when talking to young children. Since the sentences are short, the words used are also simple.

e. Adults repeat themselves when giving instruction. The repetitions are more frequent the younger the age of the child is. The repetitions allow children more time to interpret adults' utterances because they do not have to remember the whole utterances.

Clark and Clark (1977: 320-321) further state that there are three things that in. Iuence the way adults talk to children. First, they have to make sure that children understand an utterance being addressed to them, and not to someone else. To do this, they can use the child's name, a special tone of voice, or get the child's attention by touching them.

Second, once they have the child's attention, they have to choose the right words and utterances to make the child understand what is being said. For example, adults will not discuss something abstract but something that the child is doing, looking at, or playing with at the moment of the speech. Third, they shall make utterances that are easy to be understood. Usually, short sentences are preferable with slow pace of speaking. 


\section{The Reasons of Using Parentese}

Although they are still young in age, children are intelligent learners. They learn things faster than adults. However, since children are still egocentric, adults need to modify their language to get closer to them. There are some reasons behind the modifications of the language. All of them aim at stimulating children's learning process in producing and comprehending language.

a. Giving general problem-solving advice

By their speech, adults give children a hint or a method rather than a solution. However, sometimes they also give direct instruction to get children involved in an activity.

b. Giving a manageable task

Some tasks are too complex for children. Thus, adults may break the tasks into smaller ones that are still challenging; but children can handle. They divide the tasks into several stages.

c. Giving advice in the form of questions

By using questions more than commands, adults challenge children to think and elaborate the answer as well.

\section{Parentese: Its Benefit in Language Learning}

The most important factor leading to the success of learning a certain language, whether the first the mother tongue or the second language, is language exposure. Whenever children are exposed more to a certain language, their learning will result better than they who are not exposed directly to the language. The language exposures that young children receive are mainly from their parents and people in the surrounding. Thus, the way these people communicate with the children is significant enough for the development of the children's language.

Investigating the process of how children learn language and also the characteristics of parentese and baby talk, there are some benefits that can be unveiled regarding the use of parentese or baby talk in relation to language learning. The benefits are that young children:

1. Develop more vocabulary

The speech that parents and others used in talking to children is usually around the concept of here and now about what is happening in the 
immediate environment and not about remote objects and events. The vocabulary used is simple and short. For example, consonant plus vowel word patterns such as mama are preferable than the more complex sound patterns such as mother. This will provide children easy pronunciation of words that they will enjoy to pronounce.

The words parents use in speaking to young children anticipate the nature of the child's world (Brown in Clark and Clark, 1977: 323). Adults select their words that seem to have the most immediate relevance to what their children might want to talk about. The principle of immediacy is really held tightly when adults are talking to children. Besides the ease in pronunciation, introducing words this way enables children to relate the words with their referents. Thus, children will develop more vocabulary easily even though their pronunciations are not yet perfectly developed.

2. Understand abstract concepts easier

Although there are more concrete words learned in comparison to the abstract ones, children are sometimes presented with abstract concepts. When parents or others surrounding the children introduce abstract concepts, they usually do this with exaggerated intonation, pitch, and stress.

Parents tend to use higher pitch, slower speech, with more and clearer pauses between utterances, and they placed more distinctive stress on words that are considered important. They also frequently repeat or rephrase what they or their children say. For example, when introducing the concept hungry, which is a quite abstract, parent can use higher pitch and stress on words associated with it such as stomach and eat. They can also use gestures to accompany them. By this way, children will have better understanding on the concepts introduced, including the abstract ones.

3. Learn grammar naturally

Besides the advantages concerning with vocabulary, using parentese and baby talk help children with grammar. Generally, the speech to children is short and simplified. Although it is simplified, it is highly grammatical. Ungrammatical utterances are found to occur but rarely.

This grammatical consistency is useful to children who are searching to discover the structures which underlie utterances. They do this naturally of 
course, since parentese and baby talk are conducted in natural settings the children will find it unconsciously without being taught officially.

4. Understand conversation routines

From very early on, adults encourage children to take their turns as speaker and listener in conversation. Even when they talk to very small infants, they thrust conversational turns upon them. Whatever the children do is treated as a conversational turn, even though the adults carry most of the conversation. Once children begin to use one- and two-word utterances, adults begin to provide both implicit and explicit information about conversational turns.

One of the characteristics of parentese is that the utterances used are mostly in the form of interrogatives and imperatives. Adults use them hoping that their children will give responses to those speech acts. As a result, the children are accustomed to respond to these situations. They will understand when to take their turns in conversation without being aware that they have learned this from a very young age.

\section{E. Conclusion}

Children learn language from their language experiences. These exposures to language are from their parents and others surrounding them. When speaking to their children, adults modify their language so that children will understand it easier. This modification in language, which is the unique characteristic of talking to young children, is referred to as parentese and baby talk.

Parentese and baby talk are beneficial in language learning process. The benefits are that young children can develop more vocabulary, understand abstract concepts easier, learn grammar naturally, and understand conversation routines. In short, although parentese and baby talk are not the only factors leading to the success of language learning, they are of great contribution toward it. 


\section{Bibliography}

Clark, Herbert H. and Eve V. Clark. 1977. Psychology and Language: an Introduction to Psycholinguistics. New York: Harcourt Brace Jovanovich, Inc.

Cook, V.J. 1979. Young Children and Language. London: Edward Arnold Publishers Ltd.

Elliot, J.Allison. 1981. Child Language. Cambridge: Cambridge University Press.

Kopp, Claire B and Joanne B. Krakow. 1982. The Child Development in a Social Context. Massachusetts:Addison-Wesley Publishing Company, Inc.

Mukalel, Joseph C. 2003. Psychology of Language Learning. New Delhi: Discovery Publishing House.

Steinberg, Danny D et al. 2001. Psycholinguistics: Language, Mind and World. Essex: Longman.

Taylor, Insup and M. Martin Taylor. 1990. Psycholinguistics: Learning and Using Language. New Jersey: Prentice-Hall.

Walton, Robert I. and Henry Clay Lindgreen. 1972. Psychology of the Child. $3^{\text {rd }}$ edition. New Jersey: John Wiley \& Sons, Inc.

Yule, George. 2003. The Study of Language. Cambridge: Cambridge University Press. 